\title{
Gender Differences in Life Satisfaction: The Moderation Role of Social Support among Older Persons
}

\author{
Sarah Al-ja'freh ${ }^{1}$, Rabia Allari' ${ }^{2}$, Ayman M. Hamdan-Mansour ${ }^{3}$ \\ ${ }^{1}$ Lecturer; Department of Medical Sciences, Al-Balqa Applied University. Salt, 19117 Jordan, ${ }^{2}$ Assistant Professor, \\ Faculty of Nursing, Al Ahliyya Amman University. Salt. Jordan, ${ }^{3}$ Professor, Mental Health Nursing, School of \\ Nursing, the University of Jordan
}

\begin{abstract}
Introduction: Life satisfaction among older persons is one significant component of quality of life. However, differences related to gender and moderation role of social support might affect life satisfaction. The purpose of this study was to examine the moderation effect of perceived social support on the relationship between gender and life satisfaction among older persons.
\end{abstract}

Method: A predictive-exploratory approach was used. Data collected from 966 persons at age of 60 years or older using a structured interview format.

Results: In general, older persons had moderate to a high level of life satisfaction and perceived social support. Perceived social support had a significant moderation effect on the relationship between gender and life satisfaction $\left(\mathrm{F}_{7,913}=52.37, \mathrm{p}<.001 ; R^{2}=.152\right)$.

Conclusion: Life satisfaction among older persons is influenced by social support indicating importance of creating and enhancing the supportive system available to older persons.

Keywords: Life Satisfaction; Older Persons; Social Support; Gender.

\section{Introduction}

Worldwide, number of older persons, aged 60 years or above, by the year 2030 will reach $1.4^{[1]}$. By $2050,80 \%$ of older people will be living in low- and middle-income countries $^{[2]}$. The elderly population in Jordan (over age of 60) in the year 2015 reached 0.4 million, including $49.1 \%$ females and $50.9 \%$ males $^{[3]}$. The number will increase to reach $8.6 \%$ by year $2030^{[4]}$. Such a situation might impact the quality of life among older persons and their psychological wellbeing causing further health problems ${ }^{[5-7]}$. The literature indicated that older persons

\section{Correspondence Author:}

Ayman M. Hamdan Mansour RN, MSN, PhD

Professor, Mental Health Nursing, School of Nursing, the University of Jordan

e-mail: a.mansour@ju.edu.jo

Tel: 00962796383002 suffer from a myriad of physical and psychosocial morbidities which may decline their quality of life (QoL) and affecting their life satisfaction ${ }^{[8-10]}$. Older women and men found to be different in their health needs, that consequently, influencing their perception of life satisfaction and quality of life $(\mathrm{QoL})^{[11-12]}$.

Life satisfaction is one of the three major indicators of subjective well-being (SWB) that reflects the overall assessment of feelings and attitudes about one's quality of life ${ }^{[13]}$. While some researchers reported that differences among older males and females in life satisfaction existed, others found no significant differences [11]. Furthermore, studies suggested a stronger association of life satisfaction and incidence of chronic diseases in older women than in older men ${ }^{[14-15]}$. Being a female is connected to lower perception of life satisfaction which explains higher morbidity rates among older women ${ }^{[16]}$. Evidences showed that social support associate with lower health cost and higher perception of wellbeing among older persons ${ }^{[17]}$. It has also been found that 
older persons with high level of social support are more capable to maintain their health and daily activities ${ }^{[18]}$. Although literature explored adequately older person's health and well-being ${ }^{[19-22]}$, the inter connectedness of age, gender, and life satisfaction addressing the role of social support as a moderating factor has little attention. Therefore, the purpose of study was to examine the moderation effect of perceived social support from family, friends, and others on the relationship gender and life satisfaction in a sample of older persons with chronic illnesses in Jordan the specific aims were:

- To examine the moderating effect of perceived social support on the relationship between gender and life satisfaction among older person diagnosed with chronic illness?

- To test the differences in life satisfaction in relation to gender among older person diagnosed with chronic illness?

\section{Materials and Method}

Design: A cross sectional, predictive explorative design was used. Data collected using structured interview format.

Sample and Setting: A total of 996 older persons agreed and completed the questionnaire of a total of 1200 approached forming $83 \%$ response rate. Multistage sampling technique was used. Inclusion criteria included: all those above the age of 60 years and able to read and write in Arabic. Exclusion criteria included persons who are physically and mentally incompetent to answer the survey questions according to their next of kind statements.

Data collection Procedures: Data collection started after ensuring ethical approval from the University of Jordan. Privacy and confidentiality maintained and guaranteed for the participants. Structured format of data collection was used in the respondents' households by research team. The family members acted as co-signer of the consent form. The questionnaires were presented in Arabic language.

Instrumentation: The data collected using the Arabic version of scales. The instruments were:

1. The Arabic version of the Satisfaction with Life Scale $^{[23]}$ was used to measure Life satisfaction ${ }^{[24]}$. The scale is a five items scale measuring general life satisfaction. Respondents are asked to make their responses on a seven-point scale ranging from strongly disagree (1) to strongly agree (7). The higher the score the higher the life satisfaction is. The scores of the total scale range from 5 to 35 and interpreted as follow: 31- 35 (extremely satisfied), from 26-30 (satisfied), from 21-25 (slightly satisfied), 20 (neutral), from 15-19 (slightly dissatisfied), from 10-14 (dissatisfied), and $5-9$ (extremely dissatisfied). The scale has good reliability with Cronbach's alpha of $.79^{[23]}$.

2. The Arabic version of the Multidimensional Scale of Perceived Social Support ${ }^{[25]}$ was used to measure Perceived social support ${ }^{[26]}$. The scale is a 12-item tool measuring perceived social support from family, friends and others the respondents are expected to make their responses on a 7-point Likert scale ranging from very strongly disagree (1) to very strongly agree (7). The higher the score is the higher the perceived social support. This scale had good internal consistency with Cronbach's alpha of $.83^{[25]}$.

Sociodemographic factors included information related to age,gender, marital status, education level, type of chronic diseases if they have, duration of diagnosis of the disease, and smoking status.

\section{Results and Discussion}

Descriptive Characteristics: The analysis showed that age ranged from 60 to 100 years with a mean of 68.0 $(\mathrm{SD}=7.3)$. of them, $54.0 \%(\mathrm{n}=538)$ were males and $46.0 \%(\mathrm{n}=456)$ were females. The majority of the older persons $(68.6 \%, \mathrm{n}=683)$ were married, and $107 \%(\mathrm{n}=$ 107) had fulltime work. of them, $28.1 \%(n=280)$ have comorbid diagnoses of medical diagnosis, compared to $26 \%$ (260) are not diagnosed with any medical (or do not know). For more details see table 1.

Table 1: Descriptive characteristics of the older persons $(\mathrm{N}=996)$

\begin{tabular}{|l|l|c|c|}
\hline \multicolumn{2}{|l|}{ Variable } & n & \% \\
\hline \multirow{3}{*}{ Gender } & Male & 538 & 54.0 \\
\cline { 2 - 4 } & Female & 456 & 46.0 \\
\hline \multirow{3}{*}{ Education level } & $\leq$ High School & 770 & 77.3 \\
\cline { 2 - 4 } & $\geq$ High School & 226 & 22.7 \\
\hline
\end{tabular}




\begin{tabular}{|c|c|c|c|}
\hline \multicolumn{2}{|l|}{ Variable } & $\mathbf{n}$ & $\%$ \\
\hline \multirow{4}{*}{ Marital status } & Single & 21 & 2.1 \\
\hline & Married & 683 & 68.6 \\
\hline & Divorce & 34 & 3.4 \\
\hline & Widow & 257 & 25.8 \\
\hline \multirow{4}{*}{ Working status } & Don't work & 549 & 55.1 \\
\hline & Full time & 107 & 10.7 \\
\hline & Part time & 56 & 5.6 \\
\hline & Retired & 278 & 27.9 \\
\hline \multirow{2}{*}{ Smoking status } & Yes & 264 & 26.5 \\
\hline & No & 732 & 73.5 \\
\hline
\end{tabular}

Life satisfaction: The mean score of life satisfaction (LS) was 24.1 ( $\mathrm{SD}=5.9$ ) ranging from 5 to 35 with $50 \%(\mathrm{n}=498)$ have a score of 26 or higher indicating a satisfied level. According to level of satisfaction, the analysis showed that $7.8 \%(\mathrm{n}=78)$ are extremely satisfied compared to $1.9 \%(\mathrm{n}=19)$ extremely dissatisfied.
Perceived Social support (PSS): The mean total score of PSS was 62.1 $(\mathrm{SD}=12.9)$ ranging from 12 to 84. The lowest mean scores for the domains was for PSS-friends $(\mathrm{M}=17.6, \mathrm{SD}=5.8)$, while for PSS family and others were almost equal $(\mathrm{M}=22.2, \mathrm{SD}=5.1 ; \mathrm{M}=$ $22.1, \mathrm{SD}=4.9$, respectively).

Model testing: Moderation effect of perceived social support on the relationship between gender and life satisfaction

Path analysis,two-model multiple hierarchical regression analysis, was usedto examine the hypothesis. In block-1, gender was entered and in block-2 perceived social support has been entered. Initially, gender have been regressed using standardized linear regression model on life satisfaction. The analysis showed that the model was not statistically significant $(\mathrm{F}=1.91$, $\mathrm{p}$ $=.310)$. The model was able to explain only $0.5 \%\left(R^{2}=\right.$ $.005)$ of variation in life satisfaction in relation to gender among older persons. Analysis has shown that gender was not a significant predictor.

Table 3: Regression examining moderation effect of perceived social support on the relationship between gender and life satisfaction $(\mathrm{N}=996)$

\begin{tabular}{|l|c|c|c|c|}
\hline \multirow{2}{*}{ Variables } & \multicolumn{2}{|c|}{ Block 1 } & \multicolumn{2}{c|}{ Block 2 } \\
\cline { 2 - 5 } & $\boldsymbol{\beta}$ & $\boldsymbol{p}$-value & $\boldsymbol{\beta}$ & $\boldsymbol{p}$-value \\
\hline Gender & $-.523-$ & .226 & $-.549-$ & .170 \\
\hline PSS-FA & & & .163 & $\mathrm{p}<.001$ \\
\hline PSS-FR & & & .120 & $\mathrm{p}<.001$ \\
\hline PSS-OTHER & & & .256 & $\mathrm{p}<.001$ \\
\hline $\mathrm{R}^{2}$ & .005 & & .151 & \\
\hline$R_{\text {adj }}^{2}$ & .001 & & .146 & \\
\hline $\mathrm{R} 2$ change & .146 & & $p<.001$ & \\
\hline $\mathrm{e}$ & .97 & & .70 & \\
\hline
\end{tabular}

PSSFA: perceived social support from family; PSSFR: perceived social support from friends; PSSOTHER: perceived social support from others.

In block-2, in which perceived social support from family, friends and others added to test its moderation effect, the analysis showed that the model was statistically significant $(\mathrm{F}=52.37, \mathrm{p}<.001)$ with $R^{2}=0.152$ and adjusted $R^{2}=.145$. The $R^{2}$ value of .152 indicates that almost $15 \%$ of the variation in the relationship between gender and life satisfaction is related to the moderation effect of perceived social support. The variation has been improved largely with inclusion of perceived social support from model 1 to model 2 where the magnitude of $R^{2}$ changes value is .146 indicating the perceived social support has great moderation effect on the relationship between gender and life satisfaction among older person (see table 3). In general, the results infer that adding perceived social support from family, friends and others has buffered the negative influence of gender on the life satisfaction. 
Differences in life satisfaction related to selected demographics: The analysis showed no significant differences related to gender $(\mathrm{t}=.08, \mathrm{p}=941)$. However, using the univariate analysis to examine the differences between males and females in their life satisfaction controlling for type of medical diagnosis, the analysis showed a significant difference $\left(\mathrm{F}_{1,996}=8738.7, \mathrm{p}\right.$ $<.001)$. Males had higher mean score $(\mathrm{M}=24.5$, SD $=5.7)$ than females $(\mathrm{M}=23.9, \mathrm{SD}=7.1)$.significant differences found between males and females controlling for duration of medical diagnosis with mean score for males $((M=24.5, S D=5.6)$ higher than females $(M=$ 23.8, $\mathrm{SD}=7.0$ ).

\section{Discussion}

Older persons are struggling to manage their biopsychosocial needs within limited available resources in the developing countries ${ }^{[5]}$. The literature Asserted that older persons are suffering from number of psychological and physical deteriorations ${ }^{[27-30]}$. This study is extending the body of knowledge identifying the role of social support as moderating factor on the relationship between life satisfaction and gender. The findings of the study provide a new perspective of understanding that the relationship between ageing and the biopsychosocial wellbeing of older persons. We have found that social support is one core component of older persons' quality of lifedue to the effect of social support on the life satisfaction regardless of gender of the older persons. males and females are not simply similar in their social functions.Women are assuming different roles in the Arabian culture in which most of women's responsibilities are geared towards homerelated and family-related mattersindicating that women need more social support than men. However, we found that older men and women regardless of their age need an equal social support to successfully maintain their life satisfaction. The results are not in line with other

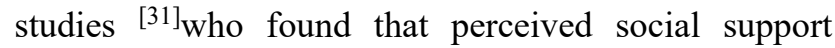
was more closely related to life satisfaction for women than for men. One explanation is that older women preserve their social roles through maintaining their strong connectedness with their adult male and female children. In Arabian culture, adult male and female children are obliged to seek more constant appraisals from their mothers than fathers in all their life matters. This would explain the higher level of social support that older women received than men. This also explains what we have also found that age and gender of older persons are not significantly related to the level of life satisfaction supporting previous report ${ }^{[30-31]}$ who found no significant differences in life satisfaction in relation to sociodemographic factors.

However, when controlling for health characteristics (type and duration of medical diagnosis)we found significant differences in life satisfaction in relation to gender in which older males were more satisfied with their lives than older females. Such findings would sustain the notion that life satisfaction is complicated within social context. This would suggest that life satisfaction among older persons cannot be measured using global life satisfaction scale. There is a need to develop a measure that emphasizing the social and psychological context of gender role among older persons.

One limitation of this study is that the sample the study is cross sectional in which a longitudinal approach measuring life satisfaction at various points of life would be more informative.

\section{Conclusion}

Given the results of the present study, specifically understanding the relationship between ageing, gender, and biopsychosocial wellbeing, the results indicated that adding perceived social support from family, friends and others has buffered the negative influence of gender on the perception of life satisfaction. Older male persons had higher life satisfaction than females controlling for health-related factors. The study implies that social support is one particular factor to consider while attempting to explain or intervene to improve quality of life among older person.

Conflicts of Interest: the authors declare no conflict

\section{Funding: None}

Ethical Clearance: The study was approved by the scientific research committee at the University of Jordan (\#10/2017-2018).

\section{References}

1. United Nation (UN) (2017) World population ageing. https://www.un.org/en/development/desa/ population/publications/pdf/ageing/WPA2017 Highlights.pdf

2. World health organization (WHO) (2018) fact sheet (ageing and health).https://www.who.int/ news-room/fact-sheets/detail/ageing-and-health

3. Help Age International (2018). http://www. 
helpage.org/global-agewatch/population-ageingdata/country-ageing-data/?country=Jordan. (Last accessed: 3 February 2020).

4. Department of Statistic (2015). Population and housing census 2015. DOS. Amman.

5. Al Khatib A, Hamdan-Mansour A, BaniHani M. Theoretical perspectives of hospitalized older patients and their health-related problems and quality of care: systematic literature review. The Open Public Health Journal 2017; 10: 215-225.

6. Khatib A, Hamdan- Mansour A, Ratrout H, Alenezi A, Chahien T. Testing the effectiveness of integrated elderly care model on quality of care and health outcomes among hospitalized elderlies in West Bank. Malaysia Journal of Public Health Medicine 2020; 20(1): 82-89.

7. Mahadeen A, Hamdan-Mansour A, Halabi J, Habashneh S, Bani Kenanah A. Psychosocial wellbeing of infertile couples in Jordan. East Mediterr Health J. 2018; 4(2):169-176.

8. Chiaranai C, Chularee S, Srithongluang S. Older people living with chronic illness. GeriatrNurs 2018; 39(5): 513-520.

9. Darawad M, Hammad S, Samarkandi SA, HamdanMansour A, Khalil A. Evaluating the psychometric properties of the Arabic version of diabetes distress scale among Arabic patients with Diabetes Mellitus.J PsychosocNursMent Health Serv 2017; 55 (9): 43-51

10. Dreidi H, Hamdan-Mansour A. Pain, Sleep Disturbance, and Quality of Life Among Palestinian Patients Diagnosed with Cancer. J Cancer Edu 2016; 31 (4): 796-803.

11. Zhao C, Wong L, Zhu Q, Yang H. Prevalence and correlates of chronic diseases in an elderly population: A community-based survey in Haikou. PloS one 2018; 13(6).

12. Hamdan-Mansour A, Nawafeh D, Hanouneh S, A 1 Omari H. Psychosocial aspects of patients diagnosed with Diabetes Mellitus type -II in Jordan.Int J Diabetes Dev Ctries2016; 36 (1): 65 69. DOI 10.1007/s13410-015-0423-z.

13. Diener E, Tay L. Subjective well-being and human welfare around the world as reflected in the Gallup World Poll. Int J Psychol 2015; 50(2): 135-149.

14. Rathaur A, Mishra S. Study on institutionalized and non-institutionalized elderly people. J Nurs Home Res Sci 2016; 2: pp.77-79.
15. Darawad M, Alfasfos N, Saleh Z, Saleh A, Hamdan-Mansour A. Predictors of delay in seeking treatment by Jordanian patients with acute coronary syndrome.Int EmergNurs 2016; 26: 20-25. DOI: 10.1016/j.ienj.2015.09.003.

16. Oshio T. Gender differences in the associations of life satisfaction with family and social relations among the Japanese elderly. J Cross Cult Gerontol 2012; 27(3): 259-274.

17. Böhm AW, Mielke GI, da Cruz MF, Ramires VV, Wehrmeister FC. Social support and leisure-time physical activity among the elderly: A populationbased study. J Phys Act Health 2016; 13(6): 599605 .

18. Angner E, Ghandhi J, Purvis KW, Amante D, Allison J. Daily functioning, health status, and happiness in older adults. Journal of Happiness Studies. 2013; 14(5): 1563-1574.

19. Hajian-Tilaki K, Heidari B, Hajian-Tilaki A. Are gender differences in health-related quality of life attributable to sociodemographic characteristics and chronic disease conditions in elderly people? Int J Prev Med 2017; 8.

20. Hamdan-Mansour A. Sociodemographic correlates of somatic symptoms of older persons in Jordan. Jordan Med J 2017; 51 (3): 119-130.

21. Hamdan-Mansour AM, Al Abeiat DD, Alzoghaibi IN, Ghannam BM, Hanouneh S I. Psychosocial and sociodemographic correlates of life satisfaction among patients diagnosed with cancer in Jordan. J Cancer Edu 2015; 30(1): 31-36.

22. Darawad MW, Hammad S, Mosleh S, Samarkandi OA, Hamdan-Mansour A, Khalil AA, Arabiat D. Psychosocial correlates of diabetes selfmanagement practices. Iran J Public Health 2017; 46(6): 771 .

23. Hamdan Mansour A, Shehadeh J, Puskar K, ElHneiti M, Haourani E. Investigating Physical, Psychological and Social Well-being of Older Persons in Jordan. Curr Aging Sci 2017; 10(3): 217-223.

24. Diener ED, Emmons RA, Larsen RJ, Griffin S. The satisfaction with life scale. J Person Assess 1985; 49(1): 71-75.

25. Amer N, Hamdan-Mansour A. Psychosocial predictors of suicidal ideation among patients diagnosed with chronic illnesses in Jordan.Issues Ment Health Nurs 2014; 35: 864-871. 
26. Zimet GD, Dahlem NW, Zimet SG, Farley GK. The multidimensional scale of perceived social support. J Person Assess 1988; 52(1):30-41.

27. Jaradat AKM, Abood MH. Life-satisfaction and social support among the elderly living in care homes and those living in their own homes. J Edu Psychol Sci 2016; 17(01).

28. Hamdan-Mansour A, Marmash L, Elayyan R, Hyarat S. Difference in perception between nurses and patients related to patients' health locus of control. Int J NursPract 2014; 20: 242-249.
29. Attallah M, Hamdan-Mansour A, Al-Sayyed M, Aboshaiqa A. Patient Satisfaction with the quality of nursing care provided: the Saudi experience. Int J NursPract 2013; 19: 584-590

30. Hamdan-Mansour A, Constantino R, Farrell M, Doswell W, Gallagher ME, Safadi R, Shishani K, Banimustafa R.Evaluating the Mental Health of Jordanian Women in Intimate Partner Abuse. Issues in Mental Health Nursing. 2011; 32:614-623.

31. Berg AI, Hassing LB, McClearn GE, Johansson B. What matters for life satisfaction in the oldest-old? Aging Ment Health 2016; 10(3): 257-264. 